DOI: 10.20472/IAC.2018.038.023

\author{
AVINOAM MEIR \\ Ben Gurion University of the Negev, Israel
}

\title{
INDIGENOUS MOBILITY AND MODERN ROADS: BEDOUIN AND ROAD 31 IN ISRAEL
}

\begin{abstract}
:
The transformation of the Negev Bedouin from mobile pastoral life into immobile semi-urban market economy, primarily through state intervention, has not ended Bedouin-state conflict. Even under semi-urban life, forms of spatial mobility, originating in their past tribal culture remain conflictual. This paper analyzes how the process of planning an upgrade of Road 31 in the Negev by the state violates the social order by curtailing this indigenous mobility. Over the years the Bedouin have created numerous informal dirt roads in their spaces that connect informally and illegally to the formal Road 31. These roads connect particularly to the 'unrecognized Bedouin villages' where the conflict revolves over the 'right for producing indigenous space'. The spatial syntax of these spaces, manifested through these roads, reflects the internal micro socio-political structure of Bedouin groups, facilitating secure movement for rival families thus sustaining the internal local delicate social order. The planning of the upgrade project ignored these forms of local mobility and connection to Road 31. Although the state agreed to regularize only few of these informal roads and 'intersections', most Bedouin spaces are left disrupted in terms of indigenous mobility. We conclude that: (1) the conceptual framework of the 'new mobilities paradigm' provides an opportunity for a more profound analysis of Bedouin space, and through this, (2) surfacing new significant layers of indigenous socio-spatial endogenous regulative measures that concern mobility, imported by the Bedouin from pastoral into 'settled' life; these are often overlooked by the state, perpetuating thus the spatial conflict.
\end{abstract}

\section{Keywords:}

Mobility, indigeneity, road, Bedouin 